\title{
The human gastric pathogen Helicobacter pylori has a potential acetone carboxylase that enhances its ability to colonize mice Priyanka Brahmachary ${ }^{1,2}$, Ge Wang1, Stéphane L Benoit ${ }^{1}$, Michael V Weinberg1,3, Robert J Maier ${ }^{1}$ and Timothy R Hoover*1
}

Address: ${ }^{1}$ Department of Microbiology, University of Georgia, Athens, Georgia 30602, USA, ${ }^{2}$ Department of Medicine, Division of Diabetes, Endocrinology and Metabolism, Vanderbilt University School of Medicine, Nashville, Tennessee 37232, USA and ${ }^{3}$ Merial Ltd., 115 Transtech Drive, Athens, Georgia 30601, USA

Email: Priyanka Brahmachary - priyanka.brahmachary@vanderbilt.edu; Ge Wang - gewang@uga.edu; Stéphane L Benoit - stefbens@uga.edu; Michael V Weinberg - m.v.weinberg@hotmail.com; Robert J Maier - rmaier@uga.edu; Timothy R Hoover* - trhoover@uga.edu

* Corresponding author

Published: 23 January 2008

BMC Microbiology 2008, 8:14 doi:10.1186/147|-2/80-8-14
Received: 28 March 2007

Accepted: 23 January 2008

This article is available from: http://www.biomedcentral.com/I47I-2/80/8/14

(c) 2008 Brahmachary et al; licensee BioMed Central Ltd.

This is an Open Access article distributed under the terms of the Creative Commons Attribution License (http://creativecommons.org/licenses/by/2.0), which permits unrestricted use, distribution, and reproduction in any medium, provided the original work is properly cited.

\begin{abstract}
Background: Helicobacter pylori colonizes the human stomach and is the etiological agent of peptic ulcer disease. All three $H$. pylori strains that have been sequenced to date contain a potential operon whose products share homology with the subunits of acetone carboxylase (encoded by acxABC) from Xanthobacter autotrophicus strain Py2 and Rhodobacter capsulatus strain BI0. Acetone carboxylase catalyzes the conversion of acetone to acetoacetate. Genes upstream of the putative $a c x A B C$ operon encode enzymes that convert acetoacetate to acetoacetyl-CoA, which is metabolized further to generate two molecules of acetyl-CoA.

Results: To determine if the $H$. pylori acxABC operon has a role in host colonization the $a c x B$ homolog in the mouse-adapted $H$. pylori SSI strain was inactivated with a chloramphenicolresistance (cat) cassette. In mouse colonization studies the numbers of $H$. pylori recovered from mice inoculated with the acxB:cat mutant were generally one to two orders of magnitude lower than those recovered from mice inoculated with the parental strain. A statistical analysis of the data using a Wilcoxin Rank test indicated the differences in the numbers of $H$. pylori isolated from mice inoculated with the two strains were significant at the $99 \%$ confidence level. Levels of acetone associated with gastric tissue removed from uninfected mice were measured and found to range from I0-II $0 \mu$ mols per gram wet weight tissue.

Conclusion: The colonization defect of the acxB:cat mutant suggests a role for the $a c x A B C$ operon in survival of the bacterium in the stomach. Products of the $H$. pylori acx $A B C$ operon may function primarily in acetone utilization or may catalyze a related reaction that is important for survival or growth in the host. $H$. pylori encounters significant levels of acetone in the stomach which it could use as a potential electron donor for microaerobic respiration.
\end{abstract}

\section{Background}

Helicobacter pylori is a microaerophilic, gram-negative bacterium that is a significant pathogen of the human gastric mucosa $[1,2]$. Colonization of the gastric mucosa by $H$. pylori leads to chronic inflammation that can progress to a variety of diseases, including chronic gastritis, peptic 
ulcer, gastric cancer and mucosal-associated lymphoma [3-5]. In the absence of antimicrobial therapy, the host is likely to suffer a lifetime $H$. pylori infection of the gastric mucosa.

The ability of $H$. pylori to persist in the human stomach for extended periods indicates that it is well adapted to acquire the nutrients it needs for growth in this unique niche. For example, the mucous layer of the mouse stomach contains significant amounts of molecular hydrogen (17-93 $\mu \mathrm{M}$ ) originating from metabolic activity of microbial flora in the large intestine [6]. H. pylori is capable of utilizing this molecular hydrogen as an electron donor for microaerobic respiration and a functional hydrogenase is required for successful colonization of mice by $H$. pylori $[6,7]$. Unlike many hydrogen-oxidizing bacteria, however, $H$. pylori is not capable of autotrophic $\mathrm{CO}_{2}$ fixation.

Several studies have examined the ability of $H$. pylori to utilize various carbon sources. $H$. pylori has a limited ability to acquire and metabolize sugars, an observation that is consistent with the analysis of the genomic sequences of $H$. pylori strains 22695 and J99 [8]. Glucose is the only carbohydrate that $H$. pylori is capable of utilizing which it does via the Entner-Doudoroff pathway $[9,10]$. Amino acids also serve as carbon sources for $H$. pylori and are utilized preferentially by $H$. pylori in growth media containing a mixture of glucose and amino acids $[9,11]$. Pyruvate, a key intermediate in central metabolism, appears to be generated primarily from lactate, alanine and serine, rather than glucose in $H$. pylori $[12,13]$. Pyruvate is converted to acetyl-CoA by pyruvate:flavodoxin oxidoreductase in $H$. pylori, which can then feed into the tricarboxylic acid (TCA) cycle[14]. In addition, alanine, lactate, acetate, formate and succinate can be produced by $H$. pylori cells incubated aerobically [12]. The production of acetate and formate as metabolic products suggests the existence of a mixed-acid fermentation pathway in $H$. pylori, although oxygen is essential for growth of the bacterium [12].

Analysis of the genome sequences of $H$. pylori strains 26695, J99 and HPAG1 revealed a potential operon of three genes (designated as HP0695, HP0696 and HP0697 in $H$. pylori 26695) the products of which shared 50-63\% amino acid identity with the $\beta, \alpha$, and $\gamma$ subunits of acetone carboxylase from Xanthobacter autotrophicus strain Py2 and Rhodobacter capsulatus strain B10 [15]. Homologs of acetone carboxylase are found in a number of bacteria, but the X. autotrophicus and R. capsulatus enzymes are the best characterized. Acetone carboxylase catalyzes the ATPdependent carboxylation of acetone to acetoacetate and is required for growth of $X$. autotrophicus and $R$. capsulatus with acetone as the sole carbon source and electron donor for respiration [15-17]. X. autotrophicus acetone carboxylase has a high affinity for acetone $(\mathrm{Km}=8 \mu \mathrm{M})$ but the turnover rate of the enzyme is very slow ( $~ 45$ per min) [15]. To compensate for the low turnover rate of acetone carboxylase, $X$. autotrophicus produces high amounts of the enzyme (17-25\% of total soluble protein) when grown on acetone [15]

Genes located near the H. pylori HP0695-HP0696HP0697 operon encode enzymes shown to convert acetoacetate to acetoacetyl-CoA, which is metabolized further to acetyl-CoA $[8,18]$. Acetone, acetoacetate and $3-\beta$ hydroxybutyrate are ketone bodies produced by mammalian perivenous hepatocytes during fatty acid degradation and are used as electron donors for respiration when carbohydrates are not readily available [19]. Just as ketone bodies are important energy sources for humans when carbohydrates are not available, these compounds may serve as respiratory electron donors for $\mathrm{H}$. pylori colonizing the gastric mucosa. To determine if the HP0695HP0696-HP0697 operon has a role in host colonization we inactivated HP0696 in H. pylori strain SS1. The HP0696 mutant was compromised in its ability to colonize mice suggesting that acetone carboxylation or a related enzymatic activity catalyzed by products of the HP0695-HP0696-HP0697 operon is a significant contributing factor to host colonization.

\section{Results \\ H. pylori contains a set of genes predicted to be involved in acetone metabolism}

The three H. pylori strains whose genomes have been sequenced contain a cluster of eight conserved genes within a $10 \mathrm{~kb}$ DNA sequence, six of which encode enzymes predicted to metabolize acetone and acetoacetate to acetyl-CoA (Figs. 1 and 2). Helicobacter acinonychis, a closely related species that infects large felines, also possesses this gene cluster. As indicated above, three of these genes share homology with $a c x A B C$, although the first two genes in the operon are indicated as genes encoding hydantoin utilization protein A and methylhydantoinase, respectively, in the annotated $H$. pylori genomes. Hydantoinases catalyze the hydrolysis of 5-membered rings via hydrolysis of an internal imide bond and often have fairly broad substrate specificity. Of proteins in the database whose biochemical functions have been demonstrated, BLAST analysis revealed that the predicted products of the H. pylori genes most closely match those of the Xanthobacter sp. Py 2 acxABC operon (59-68\% amino acid identity over the entire lengths of the three predicted subunits). For the most recently sequenced $H$. pylori and $H$. acinonychis genomes the last gene of the operon is annotated as acxC $[20,21]$. Thus, the H. pylori HP0695HP0696-HP0697 operon probably encodes acetone carboxylase rather than hydantoinase, and we hence refer to this operon as $a c x A B C$. 

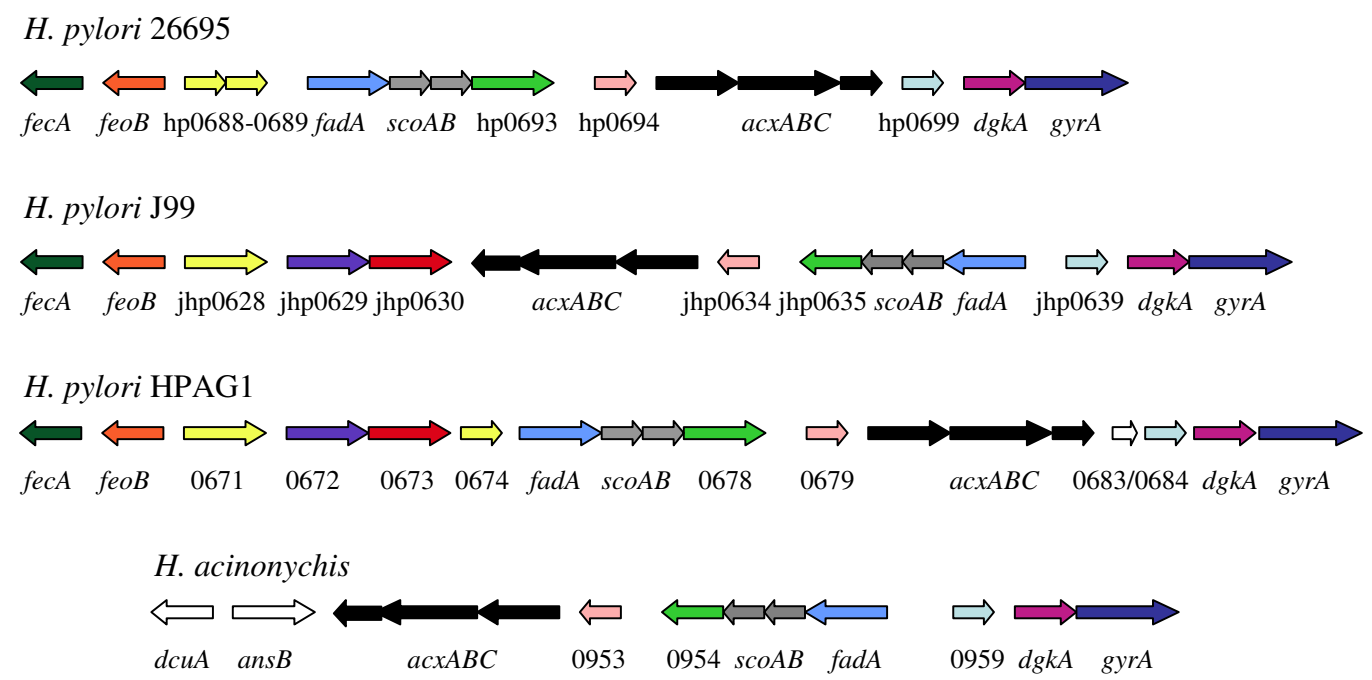

\section{Figure I}

Organization of the genes involved in acetone metabolism in $\boldsymbol{H}$. pylori and $\boldsymbol{H}$. acinonychus strains. Gene designations are indicated below each arrow (not drawn to scale). Open reading frames that were not given a gene designation in the annotated genome sequences are indicated with either an hp designation (for $H$. pylori 26695), a jhp designation (for $H$. pylori J99), or only the open reading frame number (for $H$. pylori HPAGI and A. acinonychis strain Sheeba). Orthologous genes in the four strains are the same color. The genes jhp0628 in $\mathrm{H}$. pylori $\mathrm{j} 99$ and $067 \mathrm{I}$ in $\mathrm{H}$. pylori HPAGI correspond to a fusion of hp0688 and hp0689 from H. pylori 26695. H. pylori 999 and HPAGI have two genes within this region, jhp0629 (HPAGI_0672) and jhp0630 (HPAGI_0672), that encode a type II DNA methyltransferase and a type II restriction enzyme, respectively, and are not found in $H$. pylori 26695 . Functions of the products of the genes within the acetone metabolism cluster are described in the text. The proposed functions of the products of the surrounding genes are: fecA, iron(III) dicitrate transport protein; feoB, iron(II) transport protein; $d g k A$, diacylglycerol kinase; gyrA, subunit $A$ of DNA gyrase; dcuA, anaerobic $\mathrm{C}_{4}$-dicarboxylate transporter; and ansB, asparaginase II.

Two other genes within the gene cluster, scoA (HP0691) and $\operatorname{scoB}$ (HP0692), encode succinyl CoA:acetoacetate CoA-transferase (SCOT), which catalyzes the conversion of acetoacetate plus succinyl-CoA to acetoacetyl-CoA plus succinate [18]. Acetoacetyl-CoA produced by SCOT is metabolized further by acetoacetyl-CoA thiolase, which is encoded by fadA (HP0690; gene is annotated as thl in $H$. pylori $\mathrm{J} 99$ and atoB in H. pylori HPAG1 and H. acinonychis), to generate two molecules of acetyl-CoA from acetoacetylCoA plus coenzyme A (CoA) [8]. The two remaining genes within this cluster, HP0693 and HP0694, are predicted to encode a short chain fatty acid permease and an outer membrane protein, respectively, and may function in transport of acetoacetate.

The eight genes within this putative acetone metabolism cluster are arranged the same relative to each other in the three $H$. pylori strains, but the cluster is oriented in either of the two potential directions (Fig. 1) indicating the occurrence of a DNA inversion in this region during the evolution of $H$. pylori. Alignments of DNA sequences from the three strains narrowed the site of inversion to $\sim 40 \mathrm{bp}$ downstream of the acxC homolog and 160 bp upstream of the start codon for fadA (data not shown). No large direct or inverted repeats are found near these regions that might have been involved in inversion, and so we cannot speculate as to the mechanism for this inversion. For $H$. pylori strains J99 and HPAG1, but not 26695, there are a predicted type II DNA methyltransferase (jhp0629 and HPAG1_0673) and a type II restriction enzyme (jhp0630 and HPAG1_0672) adjacent to the putative acetone metabolism gene cluster.

$H$. acinonychis possesses the putative acetone metabolism gene cluster and the genes within the cluster are in the same orientation as those in $H$. pylori J99. In H. acinonychis these genes are adjacent to $d g k A$ and $g y r A$ as they are in $H$. pylori, but are flanked on the opposite end by $d c u A$ and $a n s B$. The $f e c A$ and $f e o B$ genes, which are located near the acetone metabolism gene cluster in the H. pylori strains, are $\sim 69 \mathrm{~kb}$ from this gene cluster in $H$. acinonychis. Thus, the relative arrangement of the genes within the acetone metabolism cluster has remained remarkably conserved during the evolution of $H$. pylori and $H$. acinonychis despite the fact that the adjacent region in the genomes of these two species has undergone extensive rearrangements. 

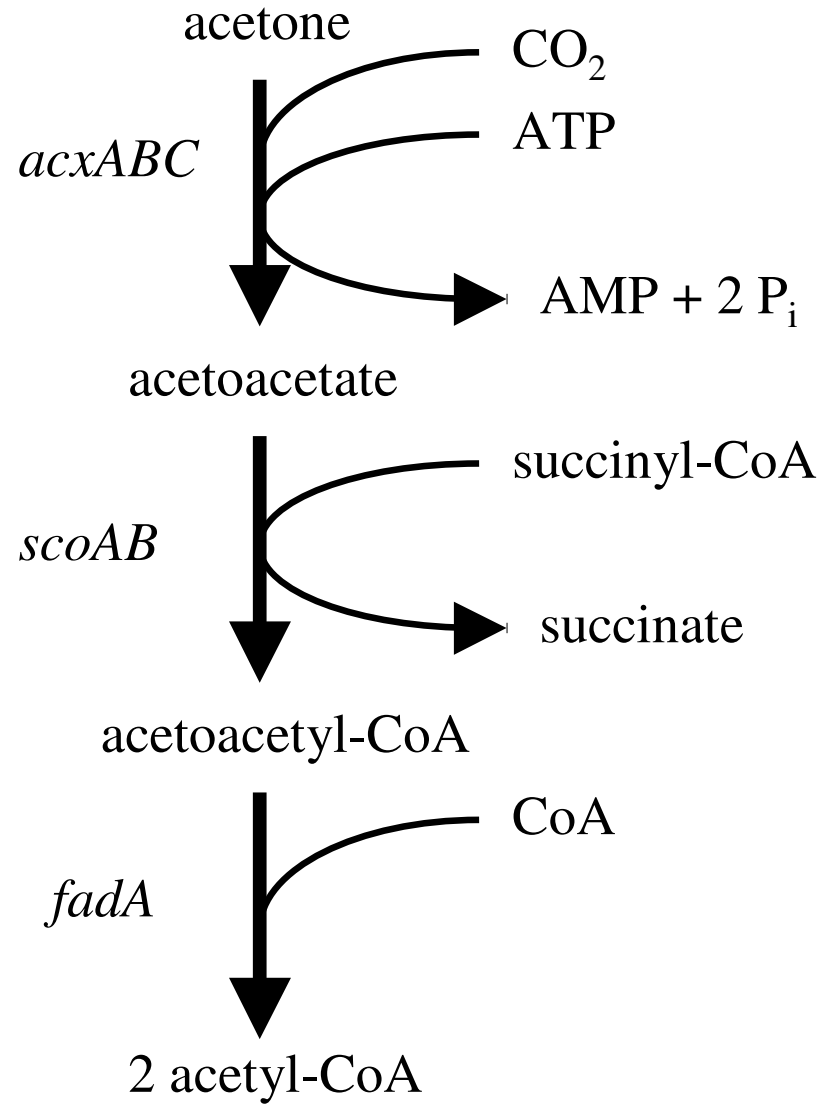

\section{Figure 2}

Proposed pathway for acetone utilization in $\boldsymbol{H}$. pylori. The proposed pathway for the conversion of acetone to acetyl-CoA in $H$. pylori and $H$. acinonychis is shown. Reactions and genes encoding the enzymes responsible for catalyzing each reaction are indicated.

The H. pylori acxB:cat mutant is deficient in its ability to colonize mice

The acxB gene in $H$. pylori SS1, which is a mouse-adapted strain, was disrupted with a chloramphenicol resistance (cat) cassette. Cultures of wild-type H. pylori SS1 and the acxB:cat mutant were grown in Mueller-Hinton broth supplemented with horse serum or a previously described defined medium [22]. Varying amounts of acetone ranging from $1.3 \mathrm{mM}$ to $26 \mathrm{mM}$ were included in the growth media to determine if acetone affected growth of either strain. Cell growth was monitored by viable cell counts as well as optical densities of cultures at various times. Including acetone in either growth media had no effect on the growth rate or final cell yield of $H$. pylori SS1 or acxB:cat mutant (data not shown). The failure of acetone to stimulate growth of $H$. pylori SS1 under the conditions tested is not unexpected since the growth media for $H$. pylori is very nutrient rich. These findings also suggest that ac $X A B C$ is not required for acetone detoxification.
The ability of the acxB:cat mutant to colonize mice was compared with that of the parental H. pylori SS1 strain in two separate trials. In each trial, eleven mice were inoculated with the wild-type strain and eleven were inoculated with the acxB:cat mutant. Three weeks post-inoculation of the mice with the $H$. pylori strains, the mice were sacrificed and the numbers of $H$. pylori in the stomachs of the animals were determined. For the mice that had been inoculated with the wild-type strain, most of the animals (19/ 22 animals) had $H$. pylori counts that were well above the detection limit, which was 500 cfu per gram stomach (Fig. 3 ). The number of $H$. pylori in samples that were above the detection limit ranged from $10^{4}-10^{6} \mathrm{cfu}$ per gram stomach. Most of the mice inoculated with the acxB:cat mutant also had measurable levels of $H$. pylori (15/22 animals), but the numbers of $H$. pylori associated with these mice were generally one to two orders of magnitude lower than those in mice that had been inoculated with the wild-type strain. A statistical analysis of the data using a Wilcoxin Rank test verified that the differences in the numbers of $H$. pylori isolated from mice inoculated with the two strains were significant at the 99\% confidence level, indicating that acetone carboxylase enhanced the ability of $H$. pylori SS1 to colonize the mouse stomach. Since we were unable to clone the acxABC operon we could not verify by complementation that the $a c x B$ mutation was responsible for the defect in colonization. However, it is unlikely that the colonization phenotype of the $a c x B$ mutant was due to polar effects since there are no additional genes in the acx$A B C$ operon in any of the three $H$. pylori strains whose genomes have been sequenced to date (Fig. 1). Moreover, the colonization defect is not likely due to attenuation or

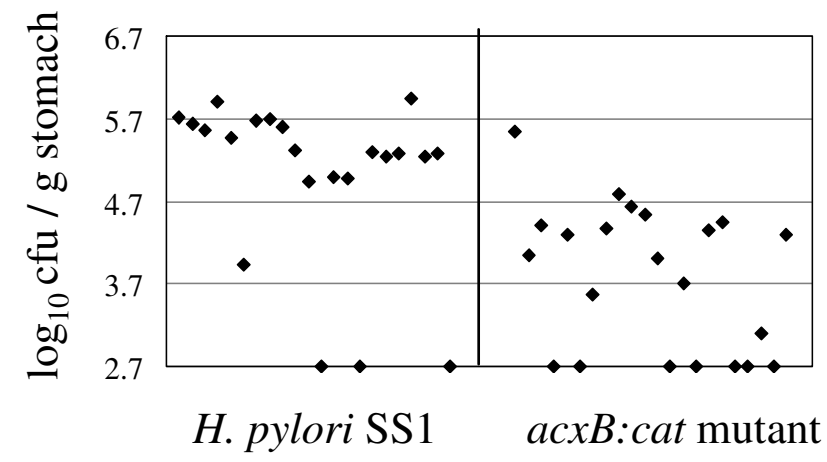

Figure 3

Mouse colonization assay of $\boldsymbol{H}$. pylori SSI and an isogenic acxB:cat mutant strain. Data are presented as a scatter plot of colony forming units per gram of stomach as determined by plate counts. Each spot represents the cfu count from one mouse, expressed as the value of $\log _{10}(\mathrm{cfu} / \mathrm{g}$ stomach) in the $Y$-axis. The base line $\left[\log _{10}(\mathrm{cfu} / \mathrm{g}\right.$ stomach $)=$ 2.7] is the detection limit of the assay, which represents the count below $500 \mathrm{cfu} / \mathrm{g}$ stomach. 
a secondary mutation since we constructed the $a c x B$ mutant in a fresh isolate of strain SS1 recovered from an infected mouse.

\section{Acetone levels in the mouse stomach}

Since the data from the mouse colonization assays suggested that ability to utilize acetone by $H$. pylori was important for effective host colonization, we wished to determine if $H$. pylori encountered significant acetone levels in the mouse stomach. Although acetone levels have been reported for various bodily fluids, we were unaware of any reports of acetone levels associated with gastric juice or tissue. Therefore, we measured acetone levels associated with mouse gastric tissue after rapidly removing the stomachs from mice and immediately placing the stomachs in sealed serum vials. Since we wished to estimate acetone levels that $H$. pylori could encounter during persistent infection, the animals used for this study were maintained on a regular feeding schedule and were sacrificed in the morning prior to receiving their normal daily food allotment. The sealed serum vials containing the mice stomachs were incubated on ice to allow the acetone associated with the gastric tissue to equilibrate with the gas phase in the vials, after which time gas phase samples were analyzed by gas chromatography. This procedure was done initially by sacrificing the animals and removing their stomachs. Similar results, however, were obtained by removing the stomachs from live animals that had been

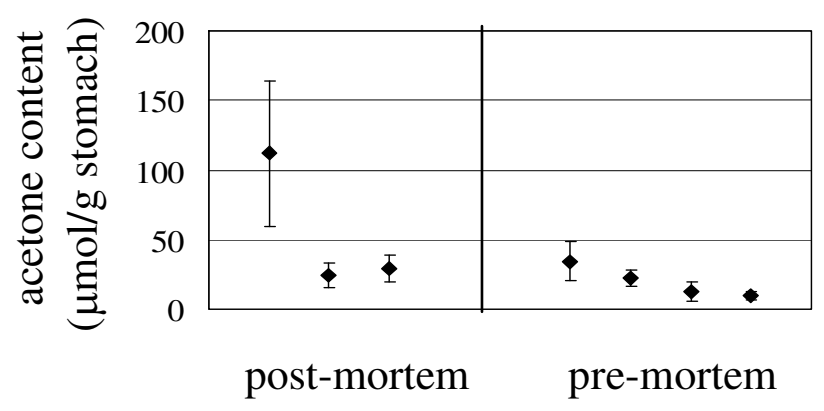

\section{Figure 4}

Acetone levels associated with mouse gastric tissue. Stomach acetone levels were determined for three mice after sacrificing the animals and immediately removing their stomachs (post-mortem), and for four mice that were anesthetized after which their stomachs were removed (premortem). Excised mouse stomachs were placed immediately in sealed vials that were then placed on ice for at least 30 min to allow acetone associated with the gastric tissue to equilibrate with the gas phase. Acetone levels in the gas phases of the vials were measured by gas chromatography and estimated from standard curves generated for each vial. Each value represents an average of at least three measurements and error bars indicate the standard deviations for each sample. anesthetized. The amount of acetone associated with gastric tissue for each individual mouse varied, ranging from $\sim 10$ to $110 \mu$ mols acetone per gram wet weight tissue (Fig. 4 ), with most values (6/7) falling in the range of 10 and $35 \mu$ mols acetone per gram wet weight tissue. These data suggest that millimolar amounts of acetone are associated with mouse gastric tissue and could be available as a potential carbon or energy source for $H$. pylori. This level of acetone associated with the mouse gastric tissue was higher than what we expected since levels of serum ketone bodies vary in humans and other mammals generally range from $<0.5 \mathrm{mM}$ to a few millimolar [23]. Acetone is produced in mammals by the spontaneous decarboxylation of acetoacetate and this decarboxylation is enhanced at low $\mathrm{pH}$, and so acetone may accumulate in the stomach due to gastric acidity.

\section{Discussion}

We provide evidence that $H$. pylori possess a functional acetone carboxylase as postulated previously by Ensign and co-workers [15]. The H. pylori acxABC operon is near the $s \operatorname{co} A B$ and $f a d B$ genes which encode the enzymes SCOT and acetoacetyl-CoA thiolase. Thus, this gene cluster encodes a set of enzymes capable of metabolizing acetone to acetyl-CoA. Acetyl-CoA produced from acetone and acetoacetate could feed into the TCA cycle to provide energy for $H$. pylori. As observed by Pflock and co-workers the $a c x A B C$ operon and other genes associated with acetone metabolism are present in H. acinonychis [24]. These genes are absent, however, in the other closely related $\varepsilon$ Proteobacteria whose genomes have been sequenced so far, which includes Helicobacter hepaticus, Campylobacter jejuni, Thiomicrospira denitrificans, and Wolinella succinogenes. The acquisition and maintenance of the acetone metabolism gene cluster in $H$. pylori and $H$. acinonychis may be related to the fact that, unlike these other related $\varepsilon$-Proteobacteria, they colonize the stomach mucosa. The clustering of these genes and the absence of orthologous genes in other closely related $\varepsilon$-Proteobacteria could indicate possible acquisition of these genes by $H$. pylori and $H$. acinonychus through lateral gene transfer. The $\mathrm{G}+\mathrm{C}$ content of this cluster of acetone metabolism genes in $\mathrm{H}$. pylori is slightly higher than the average for the whole genome, but this appears due to the products of these genes being very rich in glycine ( $10 \%$ compare to $6 \%$ genome average). Moreover, compositional characteristics of these genes, such as dinucleotide relative abundances and codon bias, are not indicative of recent lateral transfer of this region [25] (J. Mrázek, personal communication).

Jungblut and co-workers reported that $H$. pylori AcxC (HP0698) cross-reacted with antibodies from an adenocarcinoma patient, indicating that the $H$. pylori acxABC operon is expressed in the host [26]. Moreover, we show here that $H$. pylori can encounter significant levels of ace- 
tone in the mouse stomach and so this compound may serve as an important respiratory electron donor for the bacterium in the host. Consistent with this hypothesis, the $H$. pylori $a c x B$ mutant was significantly reduced in its ability to colonize the mouse stomach which we infer results from the inability of the mutant to utilize acetone as an energy source. The inability of acetone to stimulate growth of $H$. pylori SS1 in liquid culture may result from the failure of the growth media used to mimic growth conditions encountered by the bacterium when colonizing the gastric mucosa. An alternative hypothesis for the colonization defect of the $a c x B$ mutant is that acetone carboxylase is needed for detoxification of acetone. However, our failure to observe any inhibition in growth of the $a c x B$ mutant by the addition of acetone in the culture medium argues against this latter hypothesis. Another possibility is that the products of the $a c x A B C$ operon catalyze an unknown reaction that is important for survival or cell growth of $H$. pylori in the gastric mucosa. Further biochemical characterization of the products of the H. pylori ac $x A B C$ operon should help to distinguish between these possibililties.

A recent transcriptome analysis of $H$. pylori 26695 using a whole genome microarray suggested that the response regulator HP1021 strongly activated transcription of $a c x$ $A B C$ and $s c o A B$, and activated transcription of $f a d A$ and hp0693 to a lesser extent [24]. The authors of this study showed that HP1021 binds the promoter regulatory region of $a c x A B C$, suggesting that this response regulator directly mediates its effects on transcription of $a c x A B C$ and that the genes within the acetone metabolism cluster are part of a regulon controlled by HP1021. Pflock and colleagues identified 79 genes in $H$. pylori 26695 whose expression was altered in the HP1021 mutant - 51 genes were transcribed at lower levels in the mutant while 28 genes were expressed at higher levels [24]. HP1021 differs from most other response regulators in that it lacks the highly conserved phosphate-accepting aspartate residue, and a cognate histidine kinase for HP1021 has not been identified. There are conflicting reports on the transcription of HP1021 in response to acidic $\mathrm{pH}$, as well as on the transcription of $H$. pylori acxABC in response to lower $\mathrm{pH}$ [27-29]. These differences may be due to the way in which the bacteria were cultured. Although these reports conflict with regard to transcription of HP1021 in response to acidic $\mathrm{pH}$, results from both studies indicate that conditions that lead to down-regulation of HP1021 result in increased expression of acxABC. This seems counterintuitive given the apparent role of HP1021 in activating transcription of $a c x A B C$.

The only other bacterium for which regulation of the acx$A B C$ operon has been examined is $X$. autotrophicus. Transcriptional control of acxABC in $X$. autotrophicus differs from that in H. pylori. X. autotrophicus lacks a homolog of HP1021, but rather regulates transcription of $a c x A B C$ via $\sigma^{54}(\mathrm{RpoN})$ and the $\sigma^{54}$-dependent activator AcxR [15]. Although $H$. pylori possesses $\sigma^{54}$, the acxABC operon is not part of the H. pylori RpoN regulon [30].

Despite our observation that disruption of $a c x B$ adversely affects colonization of mice by $H$. pylori SS1, recent whole genome microarray studies with fifty-six globally representative strains of $H$. pylori and four $H$. acinonychis strains indicated that the acxABC genes are not present in all $H$. pylori strains [31]. It would be interesting to determine if the isolates lacking $a c x A B C$ are less competitive in colonizing their natural hosts than strains that possess these genes. Alternatively, strains lacking $a c x A B C$ may have adaptations that compensate for the lack of acetone carboxylase activity. Results from the microarray studies by Gressmann and colleagues indicated that $s c o A B$, fadA, HP0693 and HP0694 were present in all the H. pylori and $H$. acinonychis strains examined [31]. Thus, the selective pressure of maintaining the ability to utilize acetoacetate as a potential electron donor in $H$. pylori and H. acinonychis appears to be greater than that for acetone metabolism.

\section{Conclusion}

The H. pylori acxABC operon likely encodes acetone carboxylase that catalyzes the conversion of acetone to acetoacetate and is intimately associated with genes whose products are predicted to catalyze the sequential conversion of acetoacetate to acetyl-CoA. Inspection of genomes of other closely related $\varepsilon$-Proteobacteria suggests that genes involved in acetone metabolism are only present in bacteria within this subphylum that colonize the gastric mucosa. The ac $A B C$ operon was not essential for mouse colonization by $H$. pylori SS1, but it did appear to enhance colonization. Further characterization of the putative $H$. pylori acetone carboxylase and the products of the other genes within the acetone metabolism gene cluster should provide insight into how ketone bodies from the host contribute to the metabolic economies of $H$. pylori and $H$. acinonychis and how these compounds impact the ability of these bacteria to colonize their hosts.

\section{Methods \\ Bacterial strains and media}

Plasmid construction and cloning was done in E. coli strain DH5 $\alpha$ which was cultured in Luria-Bertani medium at $37^{\circ} \mathrm{C}$. H. pylori strain 26695 was used as the template for polymerase chain reaction (PCR). H. pylori SS1 was used as the wild-type strain for all experiments and was cultured on either blood agar or tryptic soy agar supplemented with $5 \%$ horse serum (TSA-serum) at $37^{\circ} \mathrm{C}$ under an atmosphere of $4 \% \mathrm{O}_{2}, 5 \% \mathrm{CO}_{2}$ and $91 \% \mathrm{~N}_{2}$. When cultured in liquid medium, H. pylori cultures were grown in 
Mueller-Hinton broth supplemented with 5\% horse serum and $30 \mu \mathrm{g} / \mathrm{ml}$ bacitracin or the defined growth medium described by Bruggrabber and co-workers [22]. Cultures (10-15 ml grown medium) were grown in 150ml serum vials sealed with $20 \mathrm{~mm}$ Teflon/silicone discs and aluminum caps and under an atmosphere of $4 \% \mathrm{O}_{2}$, $5 \% \mathrm{CO}_{2}, 10 \% \mathrm{H}_{2}, 81 \% \mathrm{~N}_{2}$. Unless indicated otherwise, when antibiotics were included in the medium they were added to the following concentrations: $100 \mu \mathrm{g} / \mathrm{ml}$ ampicillin, $30 \mu \mathrm{g} / \mathrm{ml}$ chloramphenicol, $200 \mu \mathrm{g} / \mathrm{ml}$ bacitracin $10 \mu \mathrm{g} / \mathrm{ml}$ vancomycin, and $10 \mu \mathrm{g} / \mathrm{ml}$ amphotericin $\mathrm{B}$.

\section{Inactivation of acxB (HP0696) in H. pylori SSI}

A 2.3-kb DNA fragment that carried $a c x B$ was amplified by PCR from H. pylori strain 22695 and cloned into pGEM-T (Promega). A cat cassette was introduced into this plasmid at an Eco47III site located approximately in the middle of the cloned $a c x B$. The resulting plasmid was used as a suicide vector for inactivating the chromosomal copy of $a c x B$ in $H$. pylori SS1. The suicide vector was introduced into $H$. pylori strains ATCC 43504 and SS1, a strain that can colonize mice. Because repeated passage of $H$. pylori strain SS1 on medium has been reported to result in loss of infectivity in mice, the $a c x B$ mutant was constructed in a fresh isolate of strain SS1 recovered from an infected mouse. The number of passages of $a c x B$ mutant in the SS1 strain was limited and recorded, and the mutant was stored frozen at $-80^{\circ} \mathrm{C}$. The parental SS 1 strain was maintained and stored frozen in an identical manner. We confirmed by PCR that the chromosomal copy of $a c x B$ was disrupted by allelic exchange with the plasmid-borne copy of the gene using a set of primers that flanked the site of disruption.

\section{Growth curves for $\mathbf{H}$. pylori strains}

H. pylori cells from TSA-serum plates on which the strains had been streaked on the previous day were suspended in phosphate-buffered saline (PBS) and used to inoculate liquid medium at an $\mathrm{OD}_{600}$ of 0.03 . Where indicated, acetone was added aseptically to the medium. Samples were taken at various times and cell densities were measured by light scattering at $\mathrm{OD}_{600}$. Alternatively, viable cell counts were determined following serial dilution of the samples and plating on TSA-serum. Following 4 to 5 days incubation, the numbers of colony forming units (cfu) were determined for the plates.

\section{Mouse colonization}

Mouse colonization assays were performed essentially as described earlier [32]. These procedures complied with the relevant federal guidelines and institutional policies for the care and handling of laboratory animals. Briefly, H. pylori cells were harvested after $48 \mathrm{~h}$ of growth on blood agar plates and suspended in PBS to an $\mathrm{OD}_{600}$ of 1.7. Headspace in the tube was sparged with argon to minimize oxygen exposure. These suspensions were adminis- tered to $\mathrm{C} 57 \mathrm{BL} / 6 \mathrm{~J}$ mice via oral gavage. The mice were inoculated with $H$. pylori two times (two days apart) with a dose of $1.5 \times 10^{8}$ bacterial cells/mouse. The inoculum dose was determined from reproducible standard curves of $\mathrm{OD}_{600}$ versus viable cell number from plate counts. Three weeks after the first injection, the mice were sacrificed and the stomachs were removed, weighed, and homogenized in argon-sparged PBS. Homogenates were diluted serially and the dilutions were plated on blood agar supplemented with vancomycin, amphotericin B and bacitracin $(100 \mu \mathrm{g} / \mathrm{ml})$. The plates were incubated for 5-7 days in an incubator containing $2 \% \mathrm{O}_{2}, 5 \% \mathrm{CO}_{2}$ and the balance $\mathrm{N}_{2}$, after which the plates were examined for $H$. pylori colonies.

\section{Measuring acetone levels in mouse stomachs}

Stomachs were surgically removed from pre-mortem and post-mortem C57BL/6J mice (Jackson Labs) and placed immediately in small glass vials which were half-filled with glass beads to minimize the head space. The vials were sealed with $20 \mathrm{~mm}$ Teflon/silicone discs and aluminum caps and place on ice. Samples from the head space were analyzed with a gas chromatograph equipped with a flame ionization detector (Model GC-8A, Shimadzu). Samples were removed from the head space with $1 \mathrm{ml}$ VICI Pressure-Lok Precision analytical syringe (Precision Sampling) and injected into a DB624 column $(30 \mathrm{~m} \times$ $0.53 \mathrm{~mm}, 3 \mu \mathrm{m}$ mesh). The injector and the detector temperatures were $250^{\circ} \mathrm{C}$ and air was used as the carrier at 0.4 $\mathrm{kg} / \mathrm{cm}^{2}$. Retention times and peak areas were recorded with a Chromatopac (Model CR601, Shimadzu), and the retention time for acetone under these conditions was $\sim 0.61 \mathrm{~min}$. For each sample a separate acetone standard curve was prepared as follows. The mouse stomach was removed from the vial and washed extensively in ice cold PBS. The stomach was placed back in the vial and $100 \mu \mathrm{l}$ of a known amount of acetone was applied to the tissue. The vial was resealed and placed on ice, and samples from the head space were analyzed by gas chromatography. The stomach was removed from the vial and the procedure was repeated with a different known amount of acetone. All procedures involving mice complied with the relevant federal guidelines and institutional policies for the care and handling of laboratory animals.

\section{List of abbreviations}

cfu - colony forming units

CoA - coenzyme A

PBS - phosphate buffered saline

SCOT - succinyl CoA: acetoacetate CoA-transferase

TCA - tricarboxylic acid cycle 
TSA - trypic soy agar

\section{Authors' contributions}

PB constructed the acxB:cat mutant and measured acetone levels in the mouse gastric tissue. Mouse colonization assays were done by GW and RJM. Growth analysis experiments were done by SB and MVW. TRH conceived of the study, participated in the design and coordination of experiments, and helped draft the manuscript. All authors read and approved the final manuscript.

\section{Acknowledgements}

This work was supported by award A1056036 to TRH and award DK6006I to RJM, both from the National Institutes of Health. We thank Todd Smith for reviewing the manuscript and Jan Mrázek for examining the compositional characteristics of the acetone metabolism gene cluster.

\section{References}

I. Blaser MJ: Helicobacter pylori: microbiology of a 'slow'bacterial infection. Trends Microbiol I 993, I:255-260.

2. Dunn BE, Cohen H, Blaser MJ: Helicobacter pylori. Clin Microbiol Rev 1997, 10:720-741.

3. Blaser MJ, Parsonnet J: Parasitism by the 'slow' bacterium Helicobacter pylori leads to altered gastric homeostasis and neoplasia. J Clin Invest 1994, 94:4-8.

4. Cover TL, Blaser MJ: Helicobacter pylori and gastroduodenal disease. Annu Rev Med 1992, 43:135-145.

5. Parsonnet J, Friedman GD, Vandersteen DP, Chang Y, Vogelman JH, Orentreich N, Sibley RK: Helicobacter pylori infection and the risk of gastric carcinoma. N Engl J Med I99|, 325: | |27-| | 3I.

6. Olson JW, Maier RJ: Molecular hydrogen as an energy source for Helicobacter pylori. Science 2002, 298: 1788-1790.

7. Maier RJ, Fu C, Gilbert J, Moshiri F, Olson JW, Plaut AG: Hydrogen uptake hydrogenase in Helicobacter pylori. FEMS Microbiol Lett 1996, 141:71-76.

8. Doig P, delonge BL, Alm RA, Brown ED, Uria-Nickelsen M, Noonan B, Mills SD, Tummino P, Carmel G, Guild BC, Moir DT, Vovis GF, Trust TJ: Helicobacter pylori physiology predicted from genomic comparison of two strains. Microbiol Mol Biol Rev 1999 , 63:675-707.

9. Mendz GL, Hazell SL, Burns BP: Glucose utilization and lactate production by Helicobacter pylori. J Gen Microbiol 1993, 139:3023-3028.

10. Mendz GL, Hazell SL, Burns BP: The Entner-Doudoroff pathway in Helicobacter pylori. Arch Biochem Biophys 1994, 3 I 2:349-356.

II. Mendz GL, Hazell SL: Glucose metabolism by Helicobacter pylori. Microbiology 1994, 140:2179-2/80.

12. Mendz GL, Hazell SL, van Gorkom L: Pyruvate metabolism in Helicobacter pylori. Arch Microbiol 1994, 162:187-192.

13. Stark RM, Suleiman MS, Hassan IJ, Greenman J, Millar MR: Amino acid utilisation and deamination of glutamine and asparagine by Helicobacter pylori. J Med Microbiol 1997, 46:793-800.

14. Hughes NJ, Chalk PA, Clayton CL, Kelly DJ: Identification of carboxylation enzymes and characterization of a novel foursubunit pyruvate:flavodoxin oxidoreductase from Helicobacter pylori. J Bacteriol 1995, I77:3953-3959.

15. Sluis MK, Larsen RA, Krum JG, Anderson R, Metcalf WW, Ensign SA: Biochemical, molecular, and genetic analyses of the acetone carboxylases from Xanthobacter autotrophicus strain Py2 and Rhodobacter capsulatus strain BIO. J Bacteriol 2002, 184:2969-2977.

16. Boyd JM, Ensign SA: ATP-dependent enolization of acetone by acetone carboxylase from Rhodobacter capsulatus. Biochemistry 2005, 44:8543-8553.

17. Sluis MK, Ensign SA: Purification and characterization of acetone carboxylase from Xanthobacter strain Py2. Proc Nat Acad Sci USA 1997, 94:8456-846।.

18. Corthesy-Theulaz IE, Bergonzelli GE, Henry H, Bachmann D, Schorderet DF, Blum AL, Ornston $\mathrm{LN}$ : Cloning and characterization of Helicobacter pylori succinyl CoA:acetoacetate CoA-trans- ferase, a novel prokaryotic member of the CoA-transferase family. J Biol Chem 1997, 272:25659-25667.

19. Garber AJ, Menzel PH, Boden G, Owen OE: Hepatic ketogenesis and gluconeogenesis in humans. J Clin Invest 1974, 54:98I-989.

20. Eppinger M, Baar C, Linz B, Raddatz G, Lanz C, Keller H, Morelli G, Gressmann H, Achtman M, Schuster SC: Who ate whom? Adaptive Helicobacter genomic changes that accompanied a host jump from early humans to large felines. PLoS Genet 2006, 2:el20.

21. Oh JD, Kling-Backhed H, Giannakis M, Xu J, Fulton RS, Fulton LA, Cordum HS, Wang C, Elliot G, Edwards J, Mardis ER, Engstrand LG, Gordon Il: The complete genome sequence of a chronic atrophic gastritis Helicobacter pylori strain: Evolution during disease progression. Proc Natl Acad Sci USA 2006, 103:9999-10004.

22. Bruggraber FA, French G, Thompson RPH, Powell J]: Selective and effective bactericial activity of the cobalt (II) cation against Helicobacter pylori. Helicobacter 2004, 9:422-428.

23. Laffel L: Ketone bodies: a review of physiology, pathophysiology and application of monitoring to diabetes. Diabetes Metab Res Rev 1999, 15:412-426.

24. Pflock M, Bathon M, Schar J, Muller SA, Mollenkopf H, Meyer TF, Beier D: The orphan response regulator HPI02I of Helicobacter pylori regulates transcription of a gene cluster presumably involved in acetone metabolism. J Bacteriol 2007, 189:2339-2349.

25. Karlin S: Detecting anomalous gene clusters and pathogenicity islands in diverse bacterial genomes. Trends Microbiol 200I, 9:335-343.

26. Jungblut PR, Bumann D, Haas G, Zimny-Arndt U, Holland P, Lamer S, Siejak F, Aebischer A, Meyer TF: Comparative proteome analysis of Helicobacter pylori. Mol Microbiol 2000, 36:71 0-725.

27. Merrell DS, Goodrich ML, Otto G, Tompkins LS, Falkow S: pH-regulated gene expression of the gastric pathogen Helicobacter pylori. Infect Immun 2003, 7 1:3529-3539.

28. Pflock M, Dietz P, Schar J, Beier D: Genetic evidence for histidine kinase HPI65 being an acid sensor of Helicobacter pylori. FEMS Microbiol Lett 2004, 234:5I-6I.

29. Wen Y, Marcus EA, Matrubuthan U, Gleeson MA, Scott DR, Sachs G: Acid-adaptive genes of Helicobacter pylori. Infect Immun 2003 71:5921-5939.

30. Niehus E, Gressmann H, Ye F, Schlapbach R, Dehio M, Dehio C, Stack A, Meyer TF, Suerbaum S, Josenhans C: Genome-wide analysis of transcriptional hierarchy and feedback regulation in the flagellar system of Helicobacter pylori. Mol Microbiol 2004, 52:947-961.

31. Gressmann H, Linz B, Ghai R, Pleissner KP, Schlapbach R, Yamaoka Y, Kraft C, Suerbaum S, Meyer TF, Achtman M: Gain and loss of multiple genes during the evolution of Helicobacter pylori. PLoS Genet 2005, I(4):e43.

32. Seyler RW Jr., Olson JW, Maier RJ: Superoxide dismutase-deficient mutants of Helicobacter pylori are hypersensitive to oxidative stress and defective in host colonization. I Bacteriol 200I, 69:4034-4040.

Publish with Bio Med Central and every scientist can read your work free of charge

"BioMed Central will be the most significant development for disseminating the results of biomedical research in our lifetime. "

Sir Paul Nurse, Cancer Research UK

Your research papers will be:

- available free of charge to the entire biomedical community

- peer reviewed and published immediately upon acceptance

- cited in PubMed and archived on PubMed Central

- yours - you keep the copyright
BioMedcentral 